\title{
Pap smear screening in antenatal women: an opportunistic way to save life
}

\author{
Sana Siddiqui ${ }^{1 *}$, Suhailur Rehman², Imam Bano', Sayeedul H. Arif ${ }^{2}$
}

\author{
${ }^{1}$ Department of Obstetrics and Gynecology, ${ }^{2}$ Department of Pathology, JN Medical College, AMU, Aligarh, Uttar \\ Pradesh, India
}

Received: 06 June 2021

Accepted: 05 July 2021

\section{*Correspondence:}

Dr. Sana Siddiqui,

E-mail: sanasiddiquidr@gmail.com

Copyright: $\odot$ the author(s), publisher and licensee Medip Academy. This is an open-access article distributed under the terms of the Creative Commons Attribution Non-Commercial License, which permits unrestricted non-commercial use, distribution, and reproduction in any medium, provided the original work is properly cited.

\begin{abstract}
Background: Cancer cervix is the most common genital tract malignancy encountered in developing countries. In India, first visit to the gynaecologist for most women is during pregnancy and it may be the only visit. Hence, prenatal care offers an excellent opportunity to implement cervical screening in patients of young age, especially in women who do not seek routine health care. Therefore, this study was conducted to know the prevalence of abnormal Pap smear among the ante-natal women and to evaluate the result in relation to various risk factors.

Methods: Cross sectional observational study conducted on 425 ante-natal women attending the antenatal clinic using questioner addressing various socio-demographic variables. Measures of central tendency calculated and result was tabulated by using chi-square test.

Results: Maximum number of cases in our study was NILM i.e.314 (74\%) followed by 68 cases of Candida (16\%), 30 cases of Bacterial vaginosis (7.1\%) and 10 cases of Trichomonas vaginalis (2.4\%). Only 3 cases of abnormal Pap smear was reported i.e. 2 of ASCUS and 1 of LSIL. Thus, prevalence of abnormal Pap smear was $0.7 \%$.

Conclusions: In country like India where organised screening programme are not available, as well as the awareness and uptake of available services by the target population is also poor; screening in pregnancy is worthwhile and may be a viable option to reduce the burden of cervical carcinoma.
\end{abstract}

Keywords: Pap smear, Screening, Antenatal

\section{INTRODUCTION}

Cancer cervix is the most common genital tract malignancy encountered in developing countries. Every year in India 122,844 women are diagnosed with cancer cervix and 67,477 die from the disease. ${ }^{1}$ Cervical cancer is the fourth most common cancer among women worldwide after breast, lung and colorectal cancer. ${ }^{2}$

Most common etiological agents include infection with Human Papilloma virus (HPV) specifically by HPV 16 and 18 subtypes. $^{3}$ Other possible risk factors are low socioeconomic status, early age at marriage, multiple sexual partners, multiple pregnancies, poor genital hygiene, malnutrition, use of oral contraceptives and hormones, genetic susceptibility and lack of awareness and life style. ${ }^{4}$

Highest rate of cervical abnormality occurs in women of reproductive age group, low socio-economic status and those who become sexually active at younger age. Most of the women having minimal knowledge about the disease and are unaware of the screening facilities for cancer and even those aware are hesitant to seek screening due to social stigma.

Multiple causative factors, potential for prevention, and the sheer threat posed by it, make cervical cancer an important disease for screening especially in countries like India. ${ }^{1}$ 
Cervical cancer starts with pre-cancerous dysplastic lesion which have high propensity to turn into malignant lesions. This is one of those cancers which are preventable either by vaccination against HPV, or by various screening procedures ensuring detection at early stage because it has a long pre-invasive state and therefore increasing cure rate $^{5}$.

Most cancers diagnosed during pregnancy are cervical and breast cancer, accounting for fifty per cent of all gestational cancers. ${ }^{6}$ Pregnancy seems to be a risk factor for cervical HPV infection or increased replication of the persisting virus due to the associated increased hormonal level or immunosuppression. ${ }^{7}$

In India, first visit to the gynaecologist for most women is during pregnancy and it may be the only visit. Hence pregnancy provides an opportunity for women of reproductive age to meet gynaecologist and discuss their health concerns and prenatal care offers an excellent opportunity to implement cervical screening in patients of young age, especially in women who do not seek routine health care. ${ }^{8,9}$

Screening women during pregnancy not only increases the coverage but also will pick up more cases with pre invasive lesion as the peak incidence of these lesions occur during the reproductive age group of 25-35 year. ${ }^{10}$

A conventional Pap smear is the standard method for cervical cancer screening. It detects $60-70 \%$ of cancer cervix and $70 \%$ of endometrial cancer. ${ }^{11}$ The incidence of abnormal Pap smear is reported to be $5-8 \%$ and $1.2 \%$ of these women end up having cervical cancer. ${ }^{12}$ It poses no risk to the fetus and is not associated with an increased rate of miscarriage and preterm labour. Pap smears being a cost effective, easy to perform test, can be carried out safely in pregnant women without interfering with natural course of pregnancy. ${ }^{11,13,14}$

The prevalence of abnormal Pap smears in pregnant women is reported to be $4.4 \%$ in a study done in Thailand. ${ }^{14}$ The prevalence is $0.9 \%, 0.3 \%$ and $0.5 \%$ in different studies done in India. ${ }^{9,11,13}$

Antenatal visit may be the only visit of a woman to a gynaecologist giving an opportunity for screening and downstaging of cervical cancer. With this in mind, present study was undertaken to determine the prevalence of abnormal Pap smear among pregnant women and to evaluate the result in relation to various risk factors.

\section{METHODS}

The cross-sectional observational study was conducted in the department of Obstetrics and Gynecology in collaboration with department of Pathology of Jawaharlal Nehru Medical College, AMU, Aligarh from 2016 to 2018. The study was approved by the institutional ethics comittee, Faculty of Medicine, AMU, Aligarh.
Written informed consent was taken from all subjects included in the study. Clinico-epidemiological and demographic details were taken from the clinical records.

Pregnant women, irrespective of their gestational age were randomly included in the study. In all cases a detailed history and examination were done. Pap smear was done using Ayers Spatula and cyto brush and sent to Cytology lab for interpretation using Bethesda system of reporting 2014. Pregnant females with history of sexual intercourse in the past 48 hours, history of vaginal medication in the past 48 hours, Women in labour and Women with premature rupture of membrane were excluded from the study.

\section{RESULTS}

425 women fulfilling the inclusion criteria were taken for Pap smear screening. Screening of all patients was done by cytology using Bethesda system of reporting, 2014, in the Department of Pathology.

Table 1: Distribution according to previous Pap smear.

\begin{tabular}{|lll|}
\hline $\begin{array}{l}\text { History of } \\
\text { previous Pap } \\
\text { smear }\end{array}$ & $\begin{array}{l}\text { No. of } \\
\text { women }\end{array}$ & Percentage \\
\hline Yes & 7 & 1.6 \\
\hline No & 418 & 98.4 \\
\hline Total & 425 & 100 \\
\hline
\end{tabular}

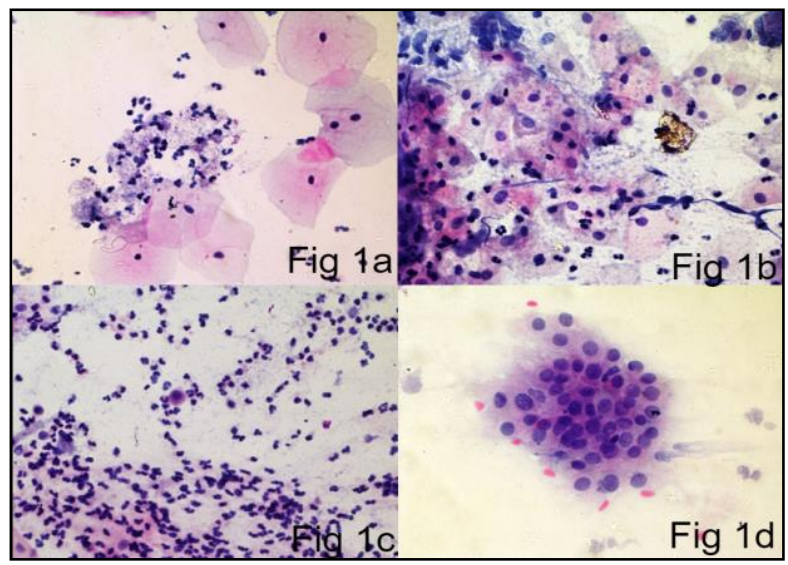

Figure 1: (A) H and E section, 400x) Candida spores seen with neutrophils and squamous cells. (B) (H and E section, 400x) Coccobacilli seen with squamous cells. (C) (H and E section, 400x) Trichomonas vaginalis bodies seen. (D) (H and E section, 400x) Low grade squamous intraepithelial lesion.

Out of 425 antenatal women participated in this study only $7(1.6 \%)$ women had history of previous Pap smear screening and rest of the 418 women (98.4\%) were screened for the first time (Table 1). 
In this study prevalence of abnormal Pap smear was $0.7 \%$ out of which ASCUS was seen in $0.5 \%$ cases and LSIL in $0.2 \%$ cases. Among the infections, Candida (16\%) was the most common cause followed by Bacterial vaginosis (7\%) and Tricomonas vaginitis $(2.4 \%)$. No cases of HSIL and Invasive carcinoma were seen. (Figure1, Table 2)

Prevalence of infection and abnormal Pap smear was found to be high in those women who were multiparous, age $>30$ years, age of marriage $<18$ years, age at first delivery $<20$ years, low socioeconomic status, illiterate and not using any contraceptive. (Table 3 )
Table 2: Result according to modified Bethesda system.

\begin{tabular}{|lll|}
\hline Cytology & Number & Percentage \\
\hline NILM (Without Infection) & 314 & 74.0 \\
\hline Candida & 68 & 16.0 \\
\hline Bacterial vaginosis & 30 & 7.1 \\
\hline Trichomonas vaginalis & 10 & 2.4 \\
\hline ASCUS & 2 & 0.47 \\
\hline LSIL & 1 & 0.23 \\
\hline HSIL & 0 & $00 \%$ \\
\hline Total & 425 & 100 \\
\hline
\end{tabular}

On chi square application, $\mathrm{p}<0.05$ and which was statistically significant.

Table 3: Result according to socio-demographic characters.

\begin{tabular}{|c|c|c|c|c|c|c|c|}
\hline & $\begin{array}{l}\text { NILM } \\
\text { (Without } \\
\text { Infection) }\end{array}$ & Candida & B.V & $\mathbf{T . V}$ & ASCUS & LSIL & $\begin{array}{l}\mathrm{N} \\
(100 \%)\end{array}$ \\
\hline \multicolumn{8}{|l|}{ Age } \\
\hline$<20$ & $18(90 \%)$ & $1(5 \%)$ & $1(5 \%)$ & $0(0 \%)$ & $0(0 \%)$ & $0(0 \%)$ & 20 \\
\hline $21-25$ & $184(82 \%)$ & $25(5 \%)$ & $12(5.4 \%)$ & $3(1.3 \%)$ & $0(0 \%)$ & $0(0 \%)$ & 224 \\
\hline $26-30$ & $104(64.5 \%)$ & $36(11 \%)$ & $14(8.6 \%)$ & $6(3.7 \%)$ & $0(0 \%)$ & $1(0.6 \%)$ & 161 \\
\hline$>31$ & $8(40 \%)$ & $6(30 \%)$ & $3(15 \%)$ & $1(5 \%)$ & $2(10 \%)$ & $0(0 \%)$ & 20 \\
\hline \multicolumn{8}{|l|}{ Parity } \\
\hline Primi & $160(89 \%)$ & $8(4.4 \%)$ & $8(4.4 \%)$ & $3(1.6 \%)$ & $0(0 \%)$ & $0(0 \%)$ & 179 \\
\hline $2^{\text {nd }} G$ & $107(78 \%)$ & $23(16 \%)$ & $7(5 \%)$ & $1(0.7 \%)$ & $0(0 \%)$ & $0(0 \%)$ & 138 \\
\hline $3^{\text {rd }} \mathrm{G}$ & $40(53 \%)$ & $25(33 \%)$ & $7(5 \%)$ & $2(2.6 \%)$ & $1(1.3 \%)$ & $0(0 \%)$ & 75 \\
\hline $4^{\text {th }} \mathrm{G}$ & $7(21 \%)$ & $12(36 \%)$ & $8(24.3 \%)$ & $4(12 \%)$ & $1(3 \%)$ & $1(3 \%)$ & 33 \\
\hline \multicolumn{8}{|c|}{ Religion } \\
\hline Muslim & $251(81 \%)$ & $31(10 \%)$ & $20(6.4 \%)$ & $6(1.9 \%)$ & $1(0.3 \%)$ & $0(0 \%)$ & 309 \\
\hline Hindu & $63(53 \%)$ & $37(32 \%)$ & $10(9 \%)$ & $4(3.4 \%)$ & $1(0.9 \%)$ & $1(0.9 \%)$ & 116 \\
\hline \multicolumn{8}{|c|}{ SE status } \\
\hline Upper & $42(95 \%)$ & $2(5 \%)$ & $0(0 \%)$ & $0(0 \%)$ & $0(0 \%)$ & $0(0 \%)$ & 44 \\
\hline Mid & $145(91 \%)$ & $10(6.3 \%)$ & $4(2.5 \%)$ & $1(0.6 \%)$ & $0(0 \%)$ & $0(0 \%)$ & 160 \\
\hline Lower & $127(57 \%)$ & $56(25 \%)$ & $26(12 \%)$ & $9(4 \%)$ & $2(0.9 \%)$ & $1(0.5 \%)$ & 221 \\
\hline \multicolumn{8}{|c|}{ Age at marriage } \\
\hline$<20$ & $29(59 \%)$ & $9(18 \%)$ & $6(12 \%)$ & $2(4 \%)$ & $2(4 \%)$ & $1(2 \%)$ & 49 \\
\hline$>20$ & $285(76 \%)$ & $59(16 \%)$ & $24(6 \%)$ & $8(2 \%)$ & $0(0 \%)$ & $0(0 \%)$ & 376 \\
\hline \multicolumn{8}{|c|}{ Age at first delivery } \\
\hline$<20$ & $11(40 \%)$ & $6(22 \%)$ & $6(22 \%)$ & $1(3.7 \%)$ & $2(7.4 \%)$ & $1(3.7 \%)$ & 27 \\
\hline$>20$ & $303(76 \%)$ & $62(15 \%)$ & $24(6 \%)$ & $9(2.2 \%)$ & $0(0 \%)$ & $0(0 \%)$ & 398 \\
\hline \multicolumn{8}{|c|}{ Contraceptive } \\
\hline Use & $181(64 \%)$ & $60(21 \%)$ & $28(10 \%)$ & $9(3.2 \%)$ & $2(0.7 \%)$ & $1(0.3 \%)$ & 281 \\
\hline Barrier & $130(98 \%)$ & $2(1.5 \%)$ & $0(0 \%)$ & $0(0 \%)$ & $0(0 \%)$ & $0(0 \%)$ & 132 \\
\hline Others & $3(25 \%)$ & $6(50 \%)$ & $2(17 \%)$ & $1(8.3 \%)$ & $0(0 \%)$ & $0(0 \%)$ & 12 \\
\hline
\end{tabular}

\section{DISCUSSION}

Cervical cancer is a preventable disease because of easy accessibility of cervix to clinical examination and different screening, diagnostic and therapeutic procedures available which are effective. As invasive squamous cell carcinoma of cervix is preceded by intraepithelial stage (CIN), which evolves over many years, there is enormous opportunity for screening with the prospects of detection of cancer at pre-clinical stage.

Cervical cancer is the most common malignancy diagnosed during pregnancy. The incidence of cervical cancer among pregnant women varies from 0.45-1 per 
1000 live births. The prevalence of abnormal Pap smear in pregnancy is dependent on the population undergoing screening and could be as high as $5-8 \% .^{15}$

Researchers have found that pregnant women are three times more likely to present with early stage cervical cancer because of regular pregnancy related obstetric examinations. ${ }^{16}$

Women who belong to low socio economic background has minimal knowledge about the disease and are unaware of the screening facilities available for cancer and even those aware are hesitant to seek screening due to social stigma. Women in our country seek health care late after the disease start producing symptoms. ${ }^{13}$

Antenatal period is a time when women come voluntarily to seek health care for pregnancy. This opportunity should be utilised to down stage cancer cervix by detection of pre invasive lesions with cytology. Abnormal Pap smears have also been reported to be associated with adverse pregnancy outcome like preterm labour etc. ${ }^{17}$

Therefore, this study was undertaken to determine the prevalence of abnormal Pap smears among pregnant women attending the antenatal clinics.

ASCUS was seen in $0.47 \%$ and LSIL in $0.23 \%$ of cases. Total number of cases with abnormal Pap smear (ASCUS and LSIL) was 3. Thus, prevalence in our study was $0.7 \%$.

The result of present study was similar to other studies done in India, such as done by Himabindu et al at Andhra Pradesh who had found it to be $0.5 \% .{ }^{11}$ In another study done by Mishra et al at Puducherry, prevalence of abnormal Pap smear in antenatal women was $0.3 \%$ in India. ${ }^{13}$ Similar study done by Prabhu et al in Tamil Nadu, found the prevalence of abnormal Pap smear to be $0.9 \%$. $^{9}$ Study done by Njaoruwong et al, the prevalence was $0.4 \% .^{18}$ (Table 4)

However, the prevalence was quite high in other countries such as in Japan, and it was reported to be $1.13 \%$ by Yamazaki et al. ${ }^{19}$ A study performed at Chonburi Hospital,
Thailand by Ingprasarn et al, the prevalence was $4.4 \% .{ }^{14}$ In a study done by Economos et al, the prevalence of abnormal Pap smear in pregnancy is dependent on the population undergoing screening and could be as high as $5-8 \% .^{15}$

In this study lack of high-risk behaviour examplesmoking, higher age of marriage and literacy could be the possible reasons for low prevalence of abnormal Pap smears.

In our study we also found a significantly higher occurrence of other infection such as candidiasis in $16 \%$, bacterial vaginosis in $7.1 \%$ and trichomonas vaginalis in $2.4 \%$ cases.

All 3 cases of abnormal Pap smear in this study was found in women having age $>30$ years. The study done by other authors have also found that CIN was more prevalent in the age group of $>30$ years. $^{20}$

In our study, two cases of ASCUS were reported in multigravida, one in third (1.3\%) and other in fourth gravid $(3 \%)$. One case of LSIL was also present in fourth gravida $(3 \%)$.

All cases of abnormal Pap smear were multiparous. This might be attributed to the hormonal and nutritional changes that occur in pregnancy, immunosuppression during pregnancy and cervical trauma during delivery. ${ }^{21}$

All cases of abnormal Pap smear [two cases of ASCUS $(0.9 \%)$ and one LSIL $(0.5 \%)]$ were found in lower class only. Poor personal hygiene, poor living conditions, unstable marriages, and early age at first intercourse are factors associated with both low socioeconomic conditions and cervical cancer. ${ }^{22}$

One of the major and important risk factor for the development of CIN and cervical cancer is early age of marriage which implicates early onset of sexual activity. ${ }^{17}$ All 3 cases of abnormal Pap smear in this study were married before the age of 20 years.

Table 4: Comparison of result of Pap smear with other studies.

\begin{tabular}{|llllllll|}
\hline Study & NILM & Candida & B.V. & T.V. & ASCUS & LSIL & HSIL \\
\hline Present study & $74 \%$ & $16 \%$ & $7.1 \%$ & $2.4 \%$ & 0.43 & 0.27 & 0 \\
\hline Himabindu et al, 2015 & $89.5 \%$ & - & - & - & 0 & $0.5 \%$ & 0 \\
\hline Prabhu et al, 2016 & $91 \%$ & $4 \%$ & - & - & $0.3 \%$ & $0.3 \%$ & $0.3 \%$ \\
\hline Mishra et al, 2015 & $84.8 \%$ & $14.6 \%$ & - & $0.3 \%$ & $0.3 \%$ & 0 & 0 \\
\hline Kurian et al, 2014 & $81 \%$ & $10.8 \%$ & $8 \%$ & - & 0.09 & 0.09 & 0 \\
\hline Ingprasarn et al, 2014 & $73.3 \%$ & $16 \%$ & $4 \%$ & $2 \%$ & $2.1 \%$ & $1.3 \%$ & $1.1 \%$ \\
\hline
\end{tabular}

Out of these $2(4 \%)$ were having ASCUS and $1(2 \%)$ was having LSIL. Sexual activities at an earlier age also have an increased risk of HPV infection which coincides with greatest metaplastic activity. ${ }^{23}$ 
It was seen that all cases of abnormal Pap smear was present in those women only who had their first child before the age of 20 years. Women who are younger than 20 years when they had their first full term pregnancy are at more risk to cancer cervix. ${ }^{24}$

In this study, $98.4 \%$ of women have never had Pap smear in the past. Only $1.6 \%$ had their Pap smear examination in the past. A Norwegian study showed that Pap smear screening during pregnancy increases the coverage of the cervical cancer screening programme. ${ }^{16}$ In other studies history of previous Pap smear was also found similar to our study i.e., $1-3 \% .^{10,14}$

All 3 cases of abnormal Pap smear, ASCUS (0.7\%) and LSIL $(0.3 \%)$ were seen in women not using any contraceptive method. Richardson et al noted that the carcinogenic factors in dysplasia originate in the semen of some men that produce dysplastic lesions of cervix and the use of mechanical barrier was found to be beneficial. ${ }^{25}$

\section{CONCLUSION}

In this study, it was found that abnormal Pap smear was seen in $0.7 \%$ of pregnant female who visited the antenatal clinic. In India, first visit to the gynaecologist for most women is during pregnancy and it may be the only visit. Hence, pregnancy provides an opportunity to screen using cervical Pap smear method, for premalignant and malignant cervical disease. As the highest rate of cervical abnormality occurs in women of reproductive age group, they can be targeted during pregnancy for screening.

Funding: No funding sources

Conflict of interest: None declared

Ethical approval: The study was approved by the Institutional Ethics Committee

\section{REFERENCES}

1. Sreedevi A, Javed R, Dinesh A. Epidemiology of cervical cancer with special focus on India. Int $\mathrm{J}$ Women's Health. 2015;7:405-14.

2. Golikeri P. A new vaccine for cervical cancer and some good hope. http://cancersupport.aarogya. com/index.php?option=com_content\&task=view\&id $=333 \&$ Itemid $=361$. Accessed on 10th November, 2009.

3. Dinc A. Pap Smear Screening Results for Turkish Pregnant Women. Asian Pacific J Cancer Prev. 2012;13(11):5835-8.

4. Walboomers JM, JacobsM, Manos MM. Human papillomavirus is necessary cause of invasive cervical cancer worldwide. J Pathology. 1999;189(1):12-9.

5. Bidus MA, Elkas JC, Scott Rose G. Cervical and vaginal cancer. Berek and Novac's gynecology.15th edition. Philadelphia: Wolters Kluwer Publishers. 2012.

6. Yang Ji, Ki Tal Kim. Gynecologic malignancy in pregnancy. Obstet Gynecol Sci. 2013;56(5):289-300.
7. Esha K, Ghosh U. K, Garg P, Geetika T, Molly M, Rani B. A study of cervical intraepithelial Neoplasia in pregnancy. J Obstet Gynaecol Ind. 2014;64(3):1936.

8. Bandyopadhyay S, Chatterjee R. HPV viral load determination during pregnancy as a possible cervical cancer risk. J Exp Clin Cancer Res. 2006;25(1):29-38.

9. Prabhu T.R.B, Velayudham D, Nethaji S, Singhal H, Venkatachalam R. Opportunistic cervical cancer screening in pregnancy. Int $\mathbf{J}$ Med Res Health sci. 2016;5(1):278-81.

10. Van Ballegooijen M, van den Akker-van Marle E, Patnick J, Lynge E, Arbyn M, Anttila A et al. Overview of important cervical cancer screening process values in European Union (EU) countries, and tentative predictions of the corresponding effectiveness and cost effectiveness. Eur J Cancer. 2000;36(17):2177-88.

11. Himabindu P, Kanwal A, Vasudha. Pap smear in Antenatal women-Routine screening in low resource settings. IOSR-JDMS. 2015;14(4):4-5.

12. Kurian C, Cyriac S. Cervical cytological changes detected by papanicolaou smear in antenatal patients attending a tertiary care centre. Eur J Can. 2014;50(4):13-14.

13. Mishra V, Dorairajan G, Neelaiah S, Chinnakali P. Prevalence of abnormal Pap smear during pregnancy in a teaching hospital in South India. Int J Reprod Contracept Obstet Gynecol. 2015;4(5):1296-9.

14. Ingprasarn A, Onaium N. Prevalence of Abnormal Conventional Pap smears in Pregnant Women, Chonburi Hospital. Thai J Obstet Gynaecol. 2014;22:137-42.

15. Economos K, Perez VN, Delke I. Abnormal cervical cytology in pregnancy: a 17-year experience. Obstet Gynecol. 1993;81(6):915-8.

16. Nygård $M$, Daltveit $A K$, Thoresen $S \emptyset$, Nygård JF. Effect of an antepartum Pap smear on the coverage of a cervical cancer screening programme: a populationbased prospective study. BMC Health Serv Res. 2007;7(1):10.

17. Hong JN, Berggren EK, Campbell SL, Smith JS, Rahangdale L. Abnormal cervical cancer screening in pregnancy and preterm delivery. Paediatric Perinat Epidemiol. 2014;28(4):297-301.

18. Ngaojaruwong N, Vuthiwong C, Punpuckdeekoon P, Thongsorn N. Prevalence of abnormal papanicolaou smear in pregnant women at Phramongkutklao Hospital. Thai J Obstet Gynaecol. 2008;16(3):179-85.

19. Yamazaki T, Inaba F, Takeda N, Huruno M, Kamemori T, Kousaka N, et al. A study of abnormal cervical cytology in pregnant women. Arch Gynecol Obstet. 2006;273(6):355-9.

20. Misra JS, Srivastava S, Singh U. Risk-factors and strategies for control of carcinoma cervix in India: hospital based cytological screening experience of 35 years. Indian J Cancer. 2009;46(2):155-9.

21. Adadevoh SW, Forkouh BK. Cervical cancer screening. Int J Gynaecol Obstest. 1993;43(1):63-4. 
22. Bustreo F, Chestnov O, Kieny MP. Comprehensive cervical cancer control. A guide to essential practice. WHO, library cataloguing-in-publication data, 2nd Ed. World Health Organization. 2014.

23. Mathew A, George PS. Trends in incidence and mortality rates of squamous cell carcinoma and adenocarcinoma of cervix-worldwide. Asian Pac J Cancer Prev. 2009;10(4):645-50.

24. Kumar S, Padubidri VG, Daftary SN. Howkins \& Bourne Shaw's text book of gynaecology 17th edition. Elsevier RELX India Pvt Ltd New Delhi. 2018;408-9.

25. Richardson AL, Lyon JB. The effect of condom use on squamous cell intraepithelial neoplasia. Am J Obstet Gyn. 1981;140(8):909-13.

Cite this article as: Siddiqui S, Rehman S, Bano I, Arif SH. Pap smear screening in antenatal women: an opportunistic way to save life. Int J Reprod Contracept Obstet Gynecol 2021;10:3158-63. 